\title{
Методология управления бизнес-субъектами рынка туристских услуг в условиях активизации конкурентного процесса
}

\author{
1) Песоцкая Е.В., ${ }^{2)}$ Селютина Л.Г. \\ ${ }^{1)}$ Санкт-Петербургский государственный экономический университет \\ Россия, 191023, Санкт-Петербург, ул. Садовая, 21 \\ E-mail: epes2@mail.ru \\ 2) Петербургский государственный университет путей сообщения Императора Александра I \\ Россия, 190031, Санкт-Петербург, Московский пр., 9 \\ E-mail: ya.slarisa@ya.ru
}

\begin{abstract}
Аннотация. Характерной чертой современного туристского рынка является активизация конкурентного процесса. Научные разработки в области управления конкурентоспособностью организаций, выводящих на рынок туристские продукты и услуги, не в полной мере отражают методологические положения современной управленческой парадигмы, концентрирующейся на развитии и эффективном использовании межсубъектных взаимодействий и бизнес-контактов. В связи с этим цель исследования - сформулировать методологические положения, обеспечивающие разработку эффективных управленческих решений в организациях туристского бизнеса, функционирующих в конкурентно-активной среде туристского рынка, с учетом возможностей для их взаимодействия, включения в сетевые образования и использования фактора корпоративной идентичности. В статье раскрыты научно-теоретические и методологические основы конкурентного поведения и обеспечения конкурентоспособности бизнес-субъектов туристского рынка и управления ею с ориентацией управленческого процесса на использование инструментов межсубъектных взаимодействий, ведущих к формированию предпринимательских сетей. Выполнен анализ принципов и методических приемов, рекомендуемых к внедрению в управление туристскими сетями, сфокусированный на конкурентную проблематику. Сформирован комплекс методических положений, использование которых способно обеспечить установление, поддержание и развитие корпоративной идентичности туристских сетей и разработку решений, реализующих на практике ее методологию. Значимость полученных результатов заключается в трансформации теоретико-методолгического базиса управления вовлеченными в интенсивную конкуренцию бизнес-субъектами рынка туристских услуг в соответствии с положениями концепции взаимодействия, сетевой теории и теории конкуренции, а также методологией корпоративной идентификации.
\end{abstract}

Ключевые слова: туристские организации, управление, конкуренция, межсубъектные взаимодействия, туристские сети, корпоративная идентичность.

Для цитирования: Песоцкая Е.В., Селютина Л.Г. 2021. Методология управления бизнес-субъектами рынка туристских услуг в условиях активизации конкурентного процесса. Экономика. Информатика, 48 (3): 495-506. DOI 10.52575/2687-0932-2021-48-3-495-506.

\section{Methodology for managing business entities of the tourist services market in the context of intensifying the competitive process}

\author{
1) Elena V. Pesotskaya, ${ }^{2)}$ Larisa G. Selyutina \\ ${ }^{1)}$ St. Petersburg State University of Economics, 21 Sadovaya str., 191023, Saint-Petersburg, Russia \\ E-mail: epes2@mail.ru \\ ${ }^{2)}$ Emperor Alexander I St. Petersburg State Transport University, 9 Moskovsky pr., \\ St. Petersburg, 190031, Russia \\ E-mail: ya.slarisa@ya.ru
}

Abstract. A characteristic feature of the modern tourist market is the intensification of the competitive process. Scientific developments in the field of managing the competitiveness of organizations that introduce tourism products and services to the market do not fully reflect the methodological provisions of the modern 
management paradigm, which focuses on the development and effective use of intersubjective interactions and business contacts. In this regard, the purpose of the study is to formulate methodological provisions that ensure the development of effective management decisions in tourism business organizations operating in a competitively active environment of the tourism market, taking into account the possibilities for their interaction, inclusion in network formations and the use of the factor of corporate identity. The article reveals the scientific, theoretical and methodological foundations of competitive behavior and ensuring the competitiveness of business entities of the tourism market and its management with the orientation of the management process towards the use of tools of intersubjective interactions leading to the formation of entrepreneurial networks. The analysis of the principles and methodological techniques recommended for implementation in the management of tourist networks, focused on competitive issues, is carried out. A complex of methodological provisions has been formed, the use of which can ensure the establishment, maintenance and development of corporate identity of tourist networks and the development of solutions that implement its methodology in practice. The significance of the results obtained lies in the transformation of the theoretical and methodological basis for managing the business entities of the tourist services market involved in intense competition in accordance with the provisions of the concept of interaction, network theory and theory of competition, as well as the methodology of corporate identification.

Key words: tourism organizations, management, competition, inter-entity interactions, tourism networks, corporate identity.

For citation: Pesotskaya E.V., Selyutina L.G. 2021. Methodology for managing business entities of the tourist services market in the context of intensifying the competitive process. Economics. Information technologies, 48 (3): 495-506 (in Russian). DOI 10.52575/2687-0932-2021-48-3-495-506.

\section{Введение}

Одной из основных тенденций, сформировавшихся в хозяйственном комплексе Российской Федерации, является активизация и нарастающая динамика конкурентного процесса. В этих условиях перед реально функционирующими бизнес-субъектами ставятся новые, более сложные управленческие задачи, касающиеся обеспечения, поддержания и развития их конкурентоспособности. Уровень сложности данных задач не однороден. В ряде отраслей и хозяйственных сфер они приобретают статус первостепенных, требующих решения силами как тактического, так и стратегического управления, что обуславливается, в первую очередь, интенсивностью конкуренции и ее возрастанием в обозримой перспективе. К числу таких сфер относится рынок туристских услуг, обладающий многочисленными и многосторонними хозяйственными связями и межсубъектными взаимодействиями. Такие взаимодействия необходимо учитывать в управлении конкурентоспособностью бизнес-субъектов туристского рынка, что влечет за собой качественное преобразование процесса формирования управленческих решений в его методологическом контуре [Pesotskaya et al., 2019].

Конкурентоспособность принято увязывать с понятием «качество», что в целом справедливо, но недостаточно для раскрытия ни социально-экономической сущности конкурентоспособности, ни методологии ее анализа и оценки, ни заложенных в ней возможностей для формирования эффективных управленческих решений. Ключевым признаком категории конкурентоспособности следует считать ее сравнительный характер, что предусматривает необходимость использования принципа вариативности в аналитических процедурах, интегрирования частных показателей и параметров в комплексном показателе конкурентоспособности, его структурного анализа и выявления конкурентных преимуществ, которые могут стать основой для принятия решений управленческого характера.

Методологический подход к управлению конкурентоспособностью бизнес-субъектов туристского рынка и формируемого ими рыночного предложения не может не учитывать такого объективного явления, как установление межсубъектных взаимодействий и контактов, создание на их основе предпринимательских сетей. Присоединение турорганизаций к сетям позволяет им достичь дополнительных преимуществ за счет снижения маркетинговых рисков 
и рисков, связанных с изменениями конкурентной среды, а также снижения издержек в технологической цепочке производства туристских продуктов и услуг, укрепления имиджа, налаживания взаимосвязей с органами государственного и регионального регулирования.

«Сетезация» туризма получила импульс к развитию в последние десятилетия, что наблюдается на международном уровне. В числе детерминант такого развития явились: процесс глобализации, в который вовлечен туризм; информатизация бизнес-процессов; становление и развитие общественных организаций, деятельность которых затрагивает туристскую проблематику. Но основным детерминирующим фактором является собственно логика производственно-рыночной деятельности бизнес-субъектов туристского рынка, функционирующих в условиях высокой конкурентной активности и стремящихся к увеличению конкурентных преимуществ за счет «вхождения» в сеть. Взаимодействия в туристских сетях придают этим сетям специфическое свойство - они позволяют идентифицировать их как известные в теории управления образования корпоративного типа. Их отличает стремление к добровольному согласованию действий, скоординированности, партнерству при отказе от «жесткого» регламентирования. Таким образованиям свойственна корпоративная идентичность, которая формируется в рамках одного из функционалов системы управления сетью - управления персоналом, задачи которого концентрируются в данном случае на определении профессиональных стандартов и достижении однородности в качестве труда.

В этом контексте поставленная в данном исследовании цель предопределила постановку и последовательное решение следующих взаимосвязанных задач:

- раскрыть методологические положения, касающиеся обеспечения конкурентоспособности современного туристского бизнеса за счет реализации таких управленческих механизмов, как формирование межсубъектных взаимодействий и создание на их основе предпринимательских сетей, рационализация управления сетями, формирование их корпоративной идентичности;

- выполнить анализ принципов и методов управления предпринимательскими сетями в туризме с учетом фактора конкуренции;

- разработать методические рекомендации, использование которых позволит формировать корпоративную идентичность рассматриваемых сетей и управленческие решения по ее обеспечению, развитию и практическому применению.

\section{Объекты и методы исследования}

Объектом исследования выступает система управления бизнес-субъектами рынка туристских услуг. В исследовании использовались общетеоретические методы, такие как метод анализа и синтеза, социально-экономического моделирования, сущностной интерпретации исследуемого объекта, научной типологизации, экспертных оценок. Применялись и предметно-ориентированные методы и приемы: методы конкурентного анализа, получения интегрированных оценок, контекстной идентификации, структурирования. Модель исследования выстроена на принципах движения от общего к частному и относится к классу логических моделей.

\section{Результаты и их обсуждение}

Современный период развития рынка туристских услуг обладает рядом отличительных характеристик. Исследователи и аналитики, интересующиеся данным рынком (его проблемами, тенденциями и перспективами), выделяют в числе таких характеристик повышение и дифференциацию спроса на туристские услуги; увеличение разнообразия рыночного предложения; активизацию бизнес-процессов в национальном туризме; изменение представлений предпринимательского сообщества о коммерческой привлекательности туристской сферы и целесообразности инвестирования проектов туристской направленности; 
совершенствование управленческого процесса как на уровне отдельных турорганизаций, так и в их интегрированных формах и целый ряд других [Федорцова, 2020].

Особое место среди отличительных характеристик занимает наблюдаемая практически во всех секторах туристского рынка активизация и интенсификация конкуренции, которая в силу своего детерминирующего воздействия видоизменяет используемый в туризме управленческий инструментарий, причем касающийся не только разработки и реализации тактических решений, но и формирования бизнес-стратегий и адекватных им стратегий управления [Selyutina et al., 2020]. Конкурентная активность как экономическая категория (применительно к различным видам товаров и услуг, а также их продуцентов) рассматривается и предметно анализируется в трудах [Селютина, 2002; Govoreanu et al., 2010; Хакимов, 2019 и др.]. Анализ заявленных этими авторами методологических позиций обнаруживает единство мнений по поводу сравнительного характера категории конкурентоспособности, ее связи с понятием «качество» и ее интегративности. Конкурентоспособность того или иного объекта (в рассматриваемом контексте - туристских услуг) определяется в ходе сопоставления ряда вариантов. Она не является абсолютным показателем, но демонстрирует преимущества одного объекта перед другим. Базовым элементом оценки конкурентоспособности является оценка качества. При определении конкурентоспособности туристской услуги учитывается множество параметров, синтезированных в ее качестве. Причем в данном случае речь идет о расширенном множестве, что обусловлено спецификой туристских услуг - многосоставных, вариативных и формирующихся на принципах комбинаторности.

В аналитической практике конкурентоспособность иногда рассматривают как синоним понятия качества, что, в принципе, объяснимо лидирующим положением последнего в оценке конкурентоспособности. Однако четко разграничивать эти понятия в процессе управления бизнес-субъектами туристского рынка совершенно необходимо. Качество есть отражение свойств (одного, нескольких или синтезированных). Оно может быть выражено соответствующими аналитической задаче абсолютными показателями, имеющими размерность. Конкурентоспособность - это всегда интегральная оценка и, что главное, всегда относительная. Она не имеет размерности. Ее итоговые сравнительные характеристики должны выражаться интегральным индексом или, в крайнем случае, если аналитику достаточно самых общих, приблизительных оценок, - в баллах. Так как конкурентоспособность всегда относительна и требует проведения процедуры сопоставления, можно утверждать, что она самым тесным образом связана с условиями туристского рынка, на котором и формируются подлежащие сопоставлению варианты. Туристские услуги с аналогичным качеством (точнее - почти аналогичным, т. к. полная аналогия услуг невозможна) может быть более или менее конкурентоспособной на различных сегментах туристского рынка, в различные периоды времени, при различиях в состоянии и динамике рыночной среды. Относительный характер конкурентоспособности туристских услуг накладывает отпечаток на управление бизнес-субъектами, функционирующими в туризме. Вопервых, он изменяет целевые ориентиры управления, не позволяя не учитывать в них фактор конкурентоспособности. Во-вторых, он выдвигает на первый план необходимость формирования в системе управления туристской организацией подсистемы, ориентированной на управление конкурентоспособностью в ее стратегических и тактических аспектах и даже на изменение самой управленческой концепции, когда последовательное развитие конкурентоспособности становится основополагающей целью.

Методология управления конкурентоспособностью, помимо теоретических представлений о сущности этой категории и фундаментальных принципах ее формирования, должна включать и объективные процессы, складывающиеся на рынке туристских услуг и достигшие высокой устойчивости. Нельзя не заметить, что в бизнес-среде туристского рынка активно развиваются межсубъектные взаимодействия с формированием образований сетевого типа - предпринимательских сетей. Становление и развитие межсубъектных взаимодействий не является случайным. В его истоках - конкурентная динамика, которая побуждает 
конкурирующие организации искать дополнительные конкурентные частности, преимущества, обусловленные взаимовыгодными взаимодействиями.

Современный взгляд на маркетинг, менеджмент, социально-экономическое управление, объединенную деятельность, получившую название «маркетинг-менеджмент» [Юлдашева, 2016; Багиев, Сомова, 2019], рассматривает несколько видов межсубъектных взаимодействий, которые формируются на различных типах рынка. Каждый из типов в той или иной мере влияет на конкурентоспособность функционирующих на них организаций. Если ориентироваться на фундаментальные положения рыночной теории, в качестве наиболее активно воздействующих на конкурентоспособность вовлеченных в рыночный процесс организаций выступают взаимодействия в цепочке «производитель-потребитель» и взаимодействия, которые формируются между производителями в процессе создания интегрированного (сложносоставного) продукта. К таким продуктам относится и туристский продукт, а также туристская услуга, обеспечивающая его потребление. С позиций сетевого подхода в фокус исследовательского интереса попадают, в первую очередь, взаимодействия между бизнес-субъектами туристского рынка, стремящиеся к согласованному функционированию, помогающему им в достижении индивидуальных целей. Но нельзя недооценивать и другой аспект сетевого подхода. Индивидуальные производители и их сеть способны эффективно функционировать лишь при достижении сбалансированности в цепочке «производитель-потребитель», что относится к классу маркетинговых задач. Соединяясь, эти аспекты образуют, по сути, конструкцию, которую принято называть системой маркетингменеджмент и закладывают основы необходимого для ее внедрения методического инструментария. При рассмотрении маркетингового аспекта проявления сетевого подхода в туристском бизнесе и возможности его использования в управлении конкурентоспособностью туристских организаций необходимо ориентироваться на особенности спроса на туристские продукты и услуги и их потребления. В литературе, посвященной отличительным свойствам туристской услуги и туристского потребления [Каныгин, Хорева, 2016; Сущинская, 2017], представлена расширенная характеристика особенностей спроса на услуги данного вида, из которых как наиболее существенные в контексте конкурентоспособности можно выделить следующие:

- неопределенный характер спроса;

- неточность уровня его удовлетворения;

- связь с социальными процессами;

- периодичность его проявления и возможность создания приверженности со стороны потребителей (носителей спроса) к определенной туристской организации, т. е. обеспечение лояльности потребителей.

Влияние данных особенностей на параметры конкурентоспособности вариативно. Первые три из них могут оказывать на конкурентоспособность бизнес-субъектов туристского рынка как положительное, так и отрицательное воздействие. Так, неопределенность спроса и приближенность его оценивания может создать как негативный, так и позитивный фон в процессе потребления. Причем вполне возможна его коррекция за счет усилий со стороны производителя в виде рекламы, пропаганды. И к негативным, и к позитивным последствиям может привести связь турбизнеса с социальными процессами. Туризм всегда находится в сфере общественных интересов. Потребительский спрос в этих условиях формируется не только исходя из индивидуальных потребностей, но и с учетом сложившихся общественных представлений. Деятельность турбизнеса и его отдельных представителей зачастую влечет за собой общественный резонанс, который, естественно, может быть как позитивным, так и негативным. Иначе проявляется влияние последней из указанных особенностей. Потребительское поведение в сфере туризма, как показывает отечественный и зарубежный опыт, часто характеризуется таким свойством как формирование приверженности к услугам одной и той же туристской организации (это свойство проявляется и в производстве многих 
других видов услуг). Потребитель, у которого сформировалось ощущение удовлетворенности процессом потребления турпродукта или туруслуги, принципиально готов к продолжению контактов с их производителем. Он приобретает мотивацию к продолжению, укреплению и развитию таких контактов, т. е. к повторному, а затем и многократному потреблению услуг одного производителя. При условии длительности таких контактов можно говорить о создании особых отношений в звене «производитель-потребитель»- отношений сетевого типа, опирающихся на наличие взаимной выгоды и устойчивые межсубъектные связи. Обладание такими контактами и само включение в рассматриваемую сеть создает дополнительные конкурентные преимущества туристским организациям. Они значительно снижают маркетинговые риски, причем как связанные с динамикой и неопределенностью спроса, так и связанные с трансформацией конкурентной среды.

Рассматривая «сетезацию» производителей турпродуктов и туруслуг - бизнессубъектов туристского рынка, следует отметить, что она влечет за собой целый ряд эффектов, непосредственно влияющих на их конкурентоспособность. Появляется возможность для координации их действий, что ведет к снижению издержек как в отношении производства и реализации туристских продуктов, так и в отношении управления организацией турбизнеса. Эти возможности дополняются согласованностью в сфере продвижения продуктов, использованием единых и универсальных средств продвижения (например, средств передачи в потребительскую среду необходимой информации). Расширяются перспективы в области проведения исследовательских разработок, ознакомления с опытом лидеров туристского рынка. Укрепляются контакты и взаимодействия с органами регулирования туристской деятельности. Предпринимательские сети туристского профиля, являясь профессиональным сообществом, оказываются способными активно воздействовать на действующие системы государственного и регионального регулирования, отстаивая свои согласованные цели и корпоративные интересы.

Значительный эффект «сетезации» туристской деятельности достигается за счет их способности пополнять и даже трансформировать территориальный социальноэкономический потенциал. Задачи территориального развития во многих туристских дестинациях всегда согласуются и учитывают потенциал туристских сетей, привязанных к их территории. На многих территориях потенциал туристских сетей становится доминирующим, определяющим: потенциал и перспективы бизнеса, связанного с туризмом; возможности для повышения уровня жизни населения; перспективы развития транспорта, логистики, другой инфраструктуры, не только напрямую, но и косвенно связанной с туризмом; возможности сохранения культурно-исторического наследия; перспективы в отношении повышения уровня занятости населения и т. п.

Внедрение сетевых форм в развитие туристской индустрии приобрело высокую активность в современном периоде. Его увязывают с процессом глобализации, с беспрецедентным уровнем развития информационных технологий. И тот, и другой фактор объективно присутствует и безусловно, является активно действующим стимулом развития туристской деятельности, и детерминантом конкурентоспособности бизнес-субъектов туристского рынка. Однако определяя характер и интенсивность их возведения, необходимо дать следующие пояснения.

Глобализация касается, в первую очередь, международного туризма. На международном уровне активно функционируют институты, оказывающие влияние на развитие туризма и обладающие инструментами, стимулирующими конкурентный процесс. Институтом, непосредственно ориентированным на поддержку международного туризма, является Всемирная туристская организация (World Tourism Organization), в течение многих десятилетий осуществляющая координацию деятельности стран, входящих в ее состав в области туризма. Перечень выполняемых ею функций включает в себя [Харламова, 2014]: укрепление международного сотрудничества в целях развития туризма; повышение качества и устойчивости в развитии туризма; ведение статистики в области туризма и разработка на ее 
основе рекомендаций управленческого характера; исследование туристских рынков; определение требований к кадрам, работающим в туриндустрии, и мероприятий по их подготовке; коммуникации и ведение унифицированной документации; развитие новых технологий в туриндустрии.

Заметное влияние на развитие международного туризма оказывают и организации, регулирующие бизнес-деятельность в целом (ВТО, ЕС, БРИКС и др.) и определяющие единую политику международной экономической деятельности.

Данные организации сформированы на международном уровне и именно поэтому рассматриваются как регулятор международного туризма. Но направления их деятельности полностью корреспондируются с ведением других видов туристского бизнеса и не могут не быть ориентирами для всех его субъектов.

Глобализация обеспечивается информационными технологиями, которые, с одной стороны, формируют ее инфраструктуру и возможности «сетезации» в туризме, а с другой стороны представляет для нее необходимый ресурс. Следует, в этом контексте, привести тезис, высказанный В.Л. Иноземцевым, согласно которому распространение информации тождественно ее самовозрастанию, что исключает применение к ней понятия редкости, при этом потребление информации не вызывает ее исчерпаемости как экономического ресурса [Иноземцев, 2019].

Использование информационных технологий свидетельствует об использовании сетевого подхода в организации туристского бизнеса и управление им. Модель турбизнеса, выстроенная на базе максимизации информационного обмена и широкого использования информационных технологий, представляет собой сетевое образование горизонтального типа, а горизонтальные связи и сам информационный ресурс позволяют получить дополнительные (организационно-информационные, коммуникативные) конкурентные преимущества всем его участникам.

При всей актуальности и популярности таких факторов, как глобализация и информатизация туристского бизнеса, важно отметить, что их не следует рассматривать как основные детерминанты развития туризма и повышения конкурентоспособности туристских организаций. Более обосновано характеризовать их как дополняющие (или вторичные), а в качестве основного (или первичного) определять изложенную выше логику производственнорыночного поведения бизнес-субъектов туристского рынка, неизбежно вовлекаемых в интенсивный конкурентный процесс и пытающихся достичь прироста конкурентоспособности за счет формирования предпринимательских сетей.

Несмотря на то, что взаимодействия в таких сетях носят «мягкий» характер, т. е. не подразумевают применение в управленческом процессе решений, однозначно регламентирующих функционирование или предписывающих определенный стиль производственно-рыночного поведения, а ограничиваются координацией и добровольным согласованием действий, речь идет об образовании корпоративного типа. Это означает, что по отношению к ним могут и должны быть использованы методы корпоративного управления с поправкой на экономическую природу управляемого объекта - предпринимательские сети в туристском бизнесе с их «мягкими» межсубъектными взаимодействиями.

С учетом этого обстоятельства представляется необходимым обратиться к известному в теории управления понятию «корпоративная идентичность», исследовать возможности ее обеспечения в условиях туристского рынка и перспективы в отношении приобретения конкурентных преимуществ кооперирующимися и формирующими предпринимательскую сеть предприятиями туристского профиля. При этом саму корпоративную идентичность (ее формирование и развитие) следует характеризовать как один из способов, с помощью которых можно обеспечить рационализацию управления сетями и системой присущих им межсубъектных взаимодействий.

Формирование корпоративной идентичности традиционно рассматривают в рамках одного из функциональных элементов системы управления - управления персоналом. Задача 
ставится следующим образом - персонал, объединенный не только структурой системы управления, но и корпоративной идентичностью, в целом работает с большей эффективностью, в полном соответствии с профессиональными стандартами и последовательно приближаясь к достижению однородности в качестве труда. В сфере туризма, применительно к предпринимательским сетям, эта задача дополняется, по меньшей мере, еще тремя.

Во-первых, корпоративная идентичность и обеспечивающие ее мероприятия позволяют достичь целостности в восприятии туристской сети как крупного обладающего хозяйственной самостоятельностью и мощным производственно-рыночным потенциалом субъекта. Причем это восприятие складывается абсолютно у всех участников туристского рынка: потребителей, конкурентов, партнеров, органов госрегулирования, представителей общественности. Данная задача может быть интерпретирована как задача маркетингового типа в части маркетинга, касающейся установления и укрепления имиджа туристской сети и бизнес-субъектов, входящих в их состав.

Во-вторых, задача формирования корпоративной идентичности, направленная на повышение качества труда, смыкается с задачей по обеспечению взаимодействий в туристских сетях. Фактор корпоративного единства способствует профессиональным контактам и, что крайне важно, позволяет оценивать и анализировать эффективность таких контактов.

В-третьих, решение данной задачи позволяет выйти за рамки управления персоналом в его инструментальном понимании (как имеющееся в любой организации управление кадрами), и перевести его на качественно новый уровень. Корпоративная идентичность туристских сетей становится стратегическим фактором, на основе которого выстраивается комплекс стратегически значимых функционалов:

- организация непрерывного процесса профессионального обучения, обеспечивающего соответствие уровня подготовки задействованных в туристской сети специалистов возрастающим требованиям;

- организация стратегического мониторинга уровня подготовленности специалистов с перспективой реализации всех возможностей мониторингового механизма;

- создание предпосылок для повышения конкурентоспособности всех организаций, входящих в туристскую сеть за счет формирования внутрисетевого ресурсного обмена;

- формирование производственно-технологических взаимодействий, при которых на каждой из стадий процесса создания туристской услуги (комплексной и структурно-сложной) или туристского продукта, обеспечивается высокое качество, детерминируемое качеством персонала;

- создание условий для обеспечения рыночной устойчивости всех участников сети, их успешной интеграции в регуляторную среду туристского рынка и, в конечном счете, использование всех преимуществ крупного бизнеса как в стратегических горизонтах, так и на тактическом и даже оперативном уровне.

Характеризуя корпоративную идентичность как организационно-управленческую категорию, важно подчеркнуть, что она существует и используется совместно с понятием отраслевой идентичности. Отраслевая идентичность формируется в том случае, когда и бизнес-субъекты туристских сетей, и задействованный в них персонал отождествляют себя с туризмом как с перспективным, обладающим социально-экономической значимостью видом деятельности. Отраслевая идентичность в туризме, как явление, появилась относительно недавно. Она связана с ростом популярности данной отрасли, очевидным возрастанием его роли в хозяйственном комплексе страны и ее регионов. Этот рост вызван целым рядом объективно протекающих процессов, в том числе и наблюдаемых на международном уровне, глобализацией, развитием постиндустриального общества, изменением общественных потребностей, информатизацией и развитием инфраструктуры. Популярность отраслевой идентичности мотивируется и национальными факторами. На отечественном туристском рынке можно наблюдать такое явление как взрывной спрос на туристские продукты, 
появившийся в последние десятилетия, который, несмотря на некоторое его снижение при ограничениях в период пандемии, сохранится и в обозримой перспективе. Можно наблюдать и широчайшую вариативность представленных на рынке турпродуктов и услуг, причем эта вариативность (а значит развитие) продолжает возрастать, поддерживая отраслевую идентичность туризма и конкурентоспособность как вида (отрасли) бизнеса.

На фоне отраслевой идентичности формируется корпоративная идентичность предпринимательских сетей туристского профиля. Популярность туризма как отрасли, безусловно, способствует позитивной идентификации как сетей, так и входящих в их состав турорганизаций, что поддерживается и действующей системой государственного и регионального регулирования, все чаще включающих туризм в число приоритетных отраслей и сфер.

Корпоративная идентичность туристских сетей слагается из двух моделей: корпоративной культуры и корпоративных компетенций. Выделение этих моделей не имеет принципиальной новизны (они рассматриваются, в частности в работах [Камерон, 2001; Tang, Naumann, 2016; Иванова и др., 2019]), но в условиях функционирования туристских сетей проявляется их специфика. Корпоративная культура в корпоративных сетях относится к разряду культур сервисного типа, отличительной чертой которых является четкая ориентация на предоставление услуг их непосредственным потребителям и развития непосредственных контактов между производителем и потребителем с их особой культурной ценностью. Сервисная культура не отрицает необходимость опираться на культурные ценности при всех других контактах и бизнес-взаимодействиях, но приоритет отдается именно носителям потребности, они же напрямую оценивают качественные параметры деятельности туристской организации, что отражается на ее конкурентоспособности. В образованиях сетевого типа (особенно тех, что формируются в рамках технологической цепочки производства туристских продуктов и услуг) сервисная культура расширяет свои возможности. В технологической цепочке каждый из ее участников может выступать в роли производителя (продукта или услуги), так и в роли их потребителя. Например, гостиничный комплекс, являющийся производителем гостиничных услуг, может выступать в качестве потребителя услуг предприятий общественного питания, бытового обслуживания, спортивного или развлекательного профиля и т. п. В этих условиях абсолютно все участники сети при всей их многочисленности и при отсутствии у многих из них непосредственной связи с конечным потребителем (туристом) сталкиваются с необходимостью культивировать ценности, свойственные сервисной культуре, и придерживаться их на всех этапах производственнохозяйственной деятельности.

Помимо «сервизации» корпоративной культуры туристской сети существует и следующая важнейшая особенность корпоративной культуры - необходимость обеспечения ее единства за счет создания внутрисетевых стандартов деятельности и следования этим стандартам. Такие стандарты (а их можно характеризовать как стандарты качества, т. е. как основу конкурентоспособности) формируются как результат управленческих усилий, причем закладываются на уровне стратегического управления туристскими сетями и входящими в них организациями-партнерами. Методология формирования стандартов качества должна предусматривать проведение прогнозно-аналитических разработок в области управления конкурентоспособностью. При реализации такой методологии необходимо использовать метод моделирования, концентрируя его на разработку прогнозно-аналитической модели, одним из элементов которой должно стать формирование стандартов качества.

Указанная особенность корпоративной культуры туристских сетей реализуется на фоне комплексности, структурной сложности турпродуктов и услуг. В этих условиях нельзя не заметить многофакторности процесса установления стандартов качества и сложности его организационного обеспечения. Становится очевидным, что только в условиях согласованности и скоординированности действий бизнес-субъектов рынка туристских услуг, 
входящих в сеть или стремящихся к образованию сети, можно говорить о возможности формирования данных стандартов.

Корпоративная культура, в совокупности ее ценностей и ценностных ориентиров, приобретает свойства управленческого механизма лишь при условии вовлечения персонала туристских сетей и образующих их организаций в ее формирование и реализацию. Данное условие можно рассматривать как предпосылку для установления корпоративной идентичности, а также как фактор, требующий учета при определении корпоративных профессиональных компетенций. Профессиональные компетенции работников, обеспечивающих функционирование туристских сетей, должны соответствовать установленным стандартам качества и нормам сервисной культуры. Часть таких компетенций носит универсальный характер и увязывается с должностными обязанностями всех работников: лояльность, ориентация на потребителя, на развитие внутрисетевых и внутриорганизационных взаимодействий, стремление к непрерывному профессиональному обучению. Другая часть - особые компетенции, которыми должен обладать работник, входящий в персонал конкретной туристской сети, и исполняющий конкретные функции и должностные обязанности. Состав таких компетенций индивидуален, а при его определении следует руководствоваться представлениями о корпоративной идентичности сети, ее конкурентных позициях в сложившихся условиях туристского рынка, перспективах развития конкурентоспособности в динамике внешних факторов. Такие представления есть результат предварительного (с точки зрения установления компетенций с их точностью и однозначностью) оценивания корпоративной идентичности. Впоследствии по результатам апробации установленных компетенций следует провести корректировку этих предварительных представлений, обеспечивая главный принцип - гармонизацию и единство корпоративной культуры и компетенций в рамках корпоративной идентичности предпринимательской сети, функционирующей в конкурентно-активной среде современного туристского рынка.

\section{Заключение}

По результатам выполненного исследования могут быть сформулированы следующие теоретические выводы и методические рекомендации:

- конкурентоспособность туристских организаций в условиях турбулентности и возрастающей неопределенности рыночной среды нуждается в применении особых управленческих механизмов. Источником и основой этих механизмов являются формирующиеся на туристском рынке межсубъектные взаимодействия, получающие организационное оформление в виде предпринимательских сетей;

- «сетезация» туристской деятельности способствует эффективной реализации побудительных стимулов конкуренции при поддержке и развитии взаимовыгодных взаимодействий между бизнес-субъектами рынка туристских услуг;

- предпринимательские сети туристского профиля, решая задачи управления конкурентоспособностью и выстраивая методологию управления и конкурентные стратегии, получают возможность для использования в качестве управленческого механизма обеспечение корпоративной идентичности сетей с присущей ей системой методов и приемов, что ведет к достижению значимого управленческого эффекта.

\section{Список литературы}

1. Багиев Г.Л., Сомова А.В. 2019. Концепция маркетинга здравого смысла и управление качеством потребления ресурсов. Национальная концепция качества: государственная и общественная защита прав потребителей: сборник тезисов докладов международной научно-практической конференции. СПб., Изд-во СПбГЭУ: 251-256.

2. Иванова М.О., Пяткова Н.В., Иванова В.С. 2019. Предпосылки формирования корпоративной идентичности персонала в процессе реализации программам дополнительного 
профессионального обучения. Транспорт России: проблемы и перспективы: материалы Международной научно-практической конференции. СПб., ИПТ РАН: 143-146.

3. Иноземцев В.Л. 2019. Экономика и политика глобализации: уроки прошлого для настоящего и будущего. Век глобализации, 2(30): 3-15.

4. Камерон К. 2001. Диагностика и измерение организационной культуры. СПб.: Питер, 320 с.

5. Каныгин Г.В., Хорева Л.В. 2016. Инновационный взгляд на сферу услуг: онтологии сервиса. Известия Санкт-Петербургского государственного экономического университета, 5(101): 78-85.

6. Селютина Л.Г. 2002. Методологические проблемы оптимизации структуры жилищного фонда и жилищного строительства в крупном городе в современных условиях. Дис. ... док. экон. наук, СПб.: СПбГИЭУ, 340 с.

7. Сущинская М.Д. 2017. Актуальные аспекты интерпретации и реализации клиентоориентированности бизнеса. Актуальные проблемы развития сферы услуг: сборник статей. СПб., Изд-во СПбГЭУ: 100-105.

8. Федорцова С.С. 2020. Современное состояние индустрии туризма. Colloquium-journal, 8 (60): 8-11.

9. Хакимов А.Х. 2019. Проблемы управления конкурентоспособностью российских предпринимательских структур и пути их решения. СПб.: СПбГЭУ, 200 с.

10.Харламова А.А. 2014. Совершенствование механизма развития туриндустрии мегаполиса в условиях глобализации. Дисс. ... канд. экон. наук, СПб.: СПбГИЭУ, 171.

11.Юлдашева О.У. 2016. Секреты маркетинга услуг: теория и технология. Управление продажами, 2: 148-149.

12.Govoreanu A. et al. 2010. Priority management - a direction towards competitiveness // Studies in Business and Economics, 5(3): 171-184.

13.Pesotskaya E.V., Selyutina L.G., Egorova O.A. 2019. Application of the engineering forecasting method in managing the competitiveness of a construction company. IOP Conference Series: Materials Science and Engineering, 698(7): 077029. DOI: 10.1088/1757-899X/698/7/077029

14.Selyutina L.G., Pesotskaya E.V., Trushkovskaya E.D. 2020. Analysis of Approaches to the Implementation of Programs for the Urban Complexes Reconstruction in Russia. IOP Conference Series: Materials Science and Engineering, 753 (3): 032044. DOI: 10.1088/1757-899X/753/3/032044

15.Tang C., Naumann S. 2016. The impact of three kinds of identity on research and development employees' incremental and radical creativity. Thinking Skills and Creativity, 21: 123. DOI: $10.1016 /$ j.tsc. 2016.06 .003

\section{References}

1. Bagiev G.L., Somova A.V. 2019. Common sense marketing concept and resource consumption quality management. National concept of quality: state and public protection of consumer rights. Proceedings of the international scientific and practical conference. SPb., Publ. SPbGEU: 251-256. (in Russian)

2. Ivanova M.O., Pyatkova N.V., Ivanova V.S. 2019. Prerequisites for the formation of corporate identity of personnel in the process of implementing additional professional training programs. Transport of Russia: Problems and Prospects. Proceedings of the International Scientific and Practical Conference. SPb., IPT RAN: 143-146. (in Russian)

3. Inozemtsev V.L. 2019. The Economy and Politics of Globalization: Lessons from the Past for the Present and the Future. Age of Globalization, 2 (30): 3-15. (in Russian)

4. Kameron K. 2001. Diagnostika i izmerenie organizatsionnoy kul'tury [Diagnostics and Measurement of Organizational Culture]. SPb.: Piter, 320

5. Kanygin G.V., Khoreva L.V. 2016. An Innovative Perspective on the Service Industry: Service Ontologies. Bulletin of St. Petersburg State University of Economics, 5 (101): 78-85. (in Russian)

6. Selyutina L.G. 2002. Metodologicheskie problemy optimizatsii struktury zhilishchnogo fonda i zhilishchnogo stroitel'stva $\mathrm{v}$ krupnom gorode $\mathrm{v}$ sovremennykh usloviyakh [Methodological problems of optimization of the structure of housing stock and housing construction in a large city in modern conditions]. Dis. dok. ekon. nauk [D. Sc. Thesis], SPb.: SPbGIEU, 340 p.

7. Sushchinskaya M.D. 2017. Topical aspects of interpretation and implementation of customer focus of business. Actual problems of development of the service sector: collection of articles. SPb., Publ. SPbGEU: 100-105. (in Russian) 
(in Russian)

9. Khakimov A.Kh. 2019. Problemy upravleniya konkurentosposobnost'yu rossiyskikh predprinimatel'skikh struktur i puti ikh resheniya [Problems of managing the competitiveness of Russian business structures and ways to solve them]. SPb.: SPbGEU, 200.

10. Kharlamova A.A. 2014. Sovershenstvovanie mekhanizma razvitiya turindustrii megapolisa v usloviyakh globalizatsii [Improving the development mechanism of the megalopolis tourism industry in the context of globalization]. Diss. kand. ekon. nauk [Ph.D dissertation in economics], SPb.: SPbGIEU, 171.

11. Yuldasheva O.U. 2016. Secrets of Service Marketing: Theory and Technology. Sales Management, 2: 148-149. (in Russian)

12. Govoreanu A. et al. 2010. Priority management - a direction towards competitiveness // Studies in Business and Economics, 5(3): 171-184.

13. Pesotskaya E.V., Selyutina L.G., Egorova O.A. 2019. Application of the engineering forecasting method in managing the competitiveness of a construction company. IOP Conference Series: Materials Science and Engineering, 698(7): 077029. DOI: 10.1088/1757-899X/698/7/077029

14. Selyutina L.G., Pesotskaya E.V., Trushkovskaya E.D. 2020. Analysis of Approaches to the Implementation of Programs for the Urban Complexes Reconstruction in Russia. IOP Conference Series: Materials Science and Engineering, 753 (3): 032044. DOI: 10.1088/1757-899X/753/3/032044

15. Tang C., Naumann S. 2016. The impact of three kinds of identity on research and development employees' incremental and radical creativity. Thinking Skills and Creativity, 21: 123. DOI: $10.1016 /$ j.tsc.2016.06.003

Конфликт интересов: о потенциальном конфликте интересов не сообщалось.

Conflict of interest: no potential conflict of interest related to this article was reported.

\section{ИНФОРМАЦИЯ ОБ АВТОРАХ}

Песоцкая Елена Владимировна, доктор экономических наук, профессор, профессор кафедры экономики и управления в сфере услуг Санкт-Петербургского государственного экономического университета, г. Санкт-Петербург, Россия

Селютина Лариса Григорьевна, доктор экономических наук, профессор, профессор кафедры экономики и менеджмента в строительстве Петербургского государственного университета путей сообщения Императора Александра I, г. Санкт-Петербург, Россия

\section{INFORMATION ABOUT THE AUTHORS}

Elena V. Pesotskaya, Doctor of Economics, Professor; Professor of the Department of Economics and Management in Services, SaintPetersburg State University of Economics, St. Petersburg, Russia

Larisa G. Selyutina, Doctor of Economics, Professor; Professor of the Department of Economics and Management in Construction, Emperor Alexander I Petersburg State Transport University, St. Petersburg, Russia 